\title{
ANALISIS PROGRAM IMPLEMENTASI GERAKAN LITERASI SEKOLAH (GLS) DENGAN PENDEKATAN GOAL-BASED EVALUATION
}

\author{
Agus Widayoko ${ }^{1}$, Supriyono Koes $\mathrm{H}^{2}$ \& Muhardjito $^{3}$ \\ ${ }^{123}$ Universitas Negeri Malang, Malang, Indonesia \\ 1widayokoagus22@gmail.com , ${ }^{2}$ suprikoes@yahoo.com \& 3 muhardjito.fmipa@um.ac.id
}

\begin{abstract}
Abstrak
Keterampilan berliterasi merupakan salah satu keterampilan dasar di abad 21. Keterampilan ini menjadi dasar keterampilan lainnya, seperti kemampuan memahami informasi secara analitis, kritis, dan reflektif. Gerakan Literasi Sekolah (GLS) adalah salah satu upaya pemerintah untuk meningkatkan keterampilan berliterasi siswa. Salah satu bentuk programnya adalah pembiasaan membaca 15 menit sebelum pembelajaran. Tujuan dari penelitian ini adalah untuk mengetahui keterlaksanaan program GLS di sekolah, kendala, dan masukan terkait perbaikan pelaksanaan program GLS. Penelitian ini menggunakan metode evaluasi Goal-Based Evaluation dalam menganalisis program GLS. Responden dari penelitian ini adalah seluruh masyarakat sekolah yang terdiri dari kepala sekolah, guru, karyawan, dan siswa se-Indonesia yang bersedia mengisi google-form yang berisi angket terkait pelaksanaan GLS. Hasil evaluasi menunjukkan bahwa 81,6\% mengatakan program GLS sudah dilaksanakan di sekolah responden, pelaksanaan pembiasaan membaca 15 menit di sekolah sudah sesuai tujuan nasional, dan $100 \%$ responden menyarankan kegiatan ini harus dilanjutkan dengan berbagai masukan.
\end{abstract}

Kata kunci: Gerakan Literasi Sekolah; Pembiasaan; Goal-Based Evaluation

\begin{abstract}
Literacy skills are one of the basic skills of the 21st century. These skills become the basis of other skills, such as the ability to understand information analytically, critically, and reflectively. The School Literacy Movement (GLS) is one of the government's efforts to improve students' literacy skills. One of the programs is reading habituation 15 minutes before learning. The purpose of this research is to know the implementation of GLS program in schools, obstacles, and feedback related to improvement of GLS program implementation. This research uses evaluation method of GoalBased Evaluation in analyzing GLS program. Respondents from this study are all school communities consisting of principals, teachers, employees, and students all over Indonesia who are willing to fill in google-form which contains questionnaires related to the implementation of GLS. The results of the evaluation indicate that 81.6\% said that the GLS program has been implemented in the
\end{abstract}


Widayoko, A., H, S., \& Muhardjito, M. (2018). ANALISIS PROGRAM IMPLEMENTASI GERAKAN LITERASI SEKOLAH (GLS) DENGAN PENDEKATAN GOAL-BASED EVALUATION. Jurnal Tatsqif, 16(1), 78-92. Retrieved from http://journal.uinmataram.ac.id/index.php/tatsqif/article/view/134

respondent's school, the reading habituation of 15 minutes in the school is in accordance with the national objectives, and $100 \%$ of respondents suggested that this activity should be continued with various inputs.

Keywords: School Literacy Movement; Habituation; Goal-Based Evaluation

\section{PENDAHULUAN}

Pada abad ke-21 ini, kemampuan berliterasi sangat diperlukan oleh pemangku kepentingan di dunia pendidikan, utamanya peserta didik. Kemampuan berliterasi peserta didik berkaitan erat dengan tuntutan keterampilan membaca yang berujung pada kemampuan memahami informasi secara analitis, kritis, dan reflektif (Faizah et al., 2016). Akan tetapi, fakta pembelajaran di sekolah saat ini belum mampu mewujudkannya dengan baik. Tuntutan keterampilan abad 21 yang harus dikuasai dan pembelajaran di sekolah yang belum mampu menumbuhkan keterampilan atau kompetensi yang dibutuhkan menjadi dasar utama literasi harus dikembangkan.

Pada tingkat sekolah menengah pertama pemahaman membaca peserta didik Indonesia masih tergolong rendah. PISA 2015 menunjukkan peserta didik Indonesia berada pada peringkat ke-64 dari 72 negara peserta (OECD, 2017). Dari hasil ini dapat dikatakan bahwa praktik pendidikan yang dilaksanakan di sekolah belum memperlihatkan fungsi sekolah sebagai organisasi pembelajaran yang berupaya menjadikan semua warganya menjadi terampil membaca untuk mendukung warga sekolah sebagai pembelajar sepanjang hayat.

Berbagai upaya sudah dilakukan oleh pemerintah pusat sebagai pemangku kepentingan di bidang pendidikan. Kementerian Pendidikan dan Kebudayaan mengembangkan gerakan literasi sekolah (GLS) yang melibatkan semua pemangku kepentingan di bidang pendidikan dari tingkat pusat sampai tingkat satuan pendidikan. Kegiatan ini juga harus mendapatkan dukungan dari pihak non-warga sekolah. Peran orang tua peserta didik, alumni, masyarakat, dunia usaha dan industri memiliki peran penting dalam keterlaksanaan program GLS (Faizah et al., 2016). 
Widayoko, A., H, S., \& Muhardjito, M. (2018). ANALISIS PROGRAM IMPLEMENTASI GERAKAN LITERASI SEKOLAH (GLS) DENGAN PENDEKATAN GOAL-BASED EVALUATION. Jurnal Tatsqif, 16(1), 78-92. Retrieved from http://journal.uinmataram.ac.id/index.php/tatsqif/article/view/134

GLS dikembangkan berdasarkan sembilan agenda prioritas (Nawacita) pemerintah pusat. GLS dikembangkan secara khusus sebagai bentuk implementasi Nawacita yang diagendakan Kemendikbud. Butir Nawacita yang dikembangkan atau sebagai landasannya adalah: meningkatkan kualitas hidup manusia dan masyarakat Indonesia; meningkatkan produktivitas rakyat dan daya saing di pasar internasional sehingga bangsa Indonesia bisa maju dan bangkit bersama bangsa-bangsa Asia lainnya; melakukan revolusi karakter bangsa; memperteguh kebinekaan dan memperkuat restorasi sosial Indonesia (Simpul, 2017). Empat butir Nawacita tersebut terkait erat dengan komponen literasi sebagai modal pembentukan sumber daya manusia yang berkualitas, produktif dan berdaya saing, berkarakter, serta nasionalis.

Salah satu implementasi GLS adalah pembiasaan membaca lima belas menit setiap hari. Lima belas menit merupakan jangkauan waktu paling efektif untuk membaca. (Dirjendikdasmen, 2016). Banyak sekali variasi implementasi GLS, ada yang menamainya jam membaca, jam literasi, ataupun lainnya. Pihak sekolah memberikan nama atau sebutan tertentu program ini dengan tujuan untuk menjadi suatu jargon yang mudah di ingat siswa bahwa sekarang adalah saatnya membaca.

Berbagai kendala muncul terkait implementasi GLS. Banyak siswa mengeluhkan ketidak disiplinannya pelaksanaan program ini, buku yang disediakan sekolah kurang variatif, ataupn beberapa hal lainnya. Sekolah memiliki peran penting untuk memaksimalkan gerakan ini. Pihak sekolah harus aktif memastikan keberlangsungan program-program GLS, melaksanakan monitoring dan evaluasi internal, berupaya membangun jejaring dengan pihak eksternal termasuk pelibatan publik dalam menggalang pelaksanaan GLS serta pencitraan GLS dengan berbagai acara, turut serta mengembangkan perpustakaan, sudut baca sekolah, dan bekerja sama dengan guru serta peserta didik untuk membangun sudut baca kelas; mengupayakan ekosistem sekolah yang literat sebagai berikut.

Evaluasi terkait efektifitas akan keterlaksanaan program GLS sangat penting dilakukan. Evaluasi merupakan kegiatan untuk mengumpulkan informasi tentang bekerjanya sesuatu, yang nantinya informasi tersebut digunakan untuk menentukan alternatif yang tepat dan akurat dalam mengambil sebuah keputusan. Hasil evaluasi ini dapat dijadikan sebagai bentuk pertanggung-jawaban kepada publik atau stakeholder tentang berbagai aspek yang terkait dengan pelaksanaan dan hasil yang 
Widayoko, A., H, S., \& Muhardjito, M. (2018). ANALISIS PROGRAM IMPLEMENTASI GERAKAN LITERASI SEKOLAH (GLS) DENGAN PENDEKATAN GOAL-BASED EVALUATION. Jurnal Tatsqif, 16(1), 78-92. Retrieved from http://journal.uinmataram.ac.id/index.php/tatsqif/article/view/134

dicapai. Dan tanpa melakukan evaluasi, tidak mungkin dapat ditemukan informasi yang akurat mengenai kekurangan dan kelebihan program GLS yang telah dilaksanakan. Tentunya proses evaluasi dilaksanakan tidak hanya satu aspek saja, tetapi harus menyeluruh. Hal tersebut dilakukan untuk mengetahui informasi atau data-data yang akurat dan komprehensif tentang kelemahan-kelemahan yang perlu diperbaiki dan kekuatan-kekuatan yang perlu dipertahankan sehingga tujuan yang direncanakan tercapai dengan baik.

Dalam proses pengimplementasikan suatu program, tentu mempunyai perbedaan dalam evaluasi. Perbedaan tersebut terjadi karena adanya perbedaan maksud dan tujuan dari suatu program. Ada berbagai macam model dalam mengevaluasi. Di sini peneliti menggunakan model evaluasi goal-based evaluation. Pendekatan ini relatif cepat untuk mengumpulkan informasi penting yang digunakan dalam perbaikan program yang sedang berjalan (Darodjat \& Wahyudhiana, 2015). Pendekatan ini mungkin digunakan pada evaluasi sumatif yang berorientasi pada kesimpulan, tetapi pendekatan ini lebih dimaksudkan untuk digunakan dalam evaluasi formatif yang bertujuan untuk memperbaiki program. Begitu juga program GLS juga memerlukan evaluasi secara lebih.

\section{LANDASAN TEORI}

Gerakan literasi sekolah (GLS) adalah salah satu upaya pemerintah dalam meningkatkan kualitas hidup manusia dalam menghadapi abad 21. GLS dilakukan secara menyeluruh dan berkelanjutan untuk menjadikan sekolah sebagai organisasi pembelajaran yang warganya literat sepanjang hayat melalui pelibatan publik (Dirjendikdasmen, 2015). Sekolah sebagai pembelajaran literat adalah sekolah yang menyenangkan dan ramah anak di mana semua warganya menunjukkan empati, kepedulian, semangat ingin tahu dan cinta pengetahuan, cakap berkomunikasi dan dapat berkontribusi kepada lingkungan sosialnya.

Tujuan adanya Gerakan Literasi Sekolah (GLS) adalah

1) Menumbuh kembangkan budaya literasi membaca dan menulis siswa di sekolah

2) Meningkatkan kapasitas warga dan lingkungan sekolah agar literat

3) Menjadikan sekolah sebagai taman belajar yang menyenangkan dan ramah agar warga sekolah mampu mengelola pengetahuan 
Widayoko, A., H, S., \& Muhardjito, M. (2018). ANALISIS PROGRAM IMPLEMENTASI GERAKAN LITERASI SEKOLAH (GLS) DENGAN PENDEKATAN GOAL-BASED EVALUATION. Jurnal Tatsqif, 16(1), 78-92. Retrieved from http://journal.uinmataram.ac.id/index.php/tatsqif/article/view/134

4) Menjaga keberlanjutan pembelajaran dengan mengahdirkan beragam buku bacaan dan mewadahi berbagai strategi membaca

Pendekatan evaluasi yang digunakan pada penelitian ini adalah goal-based evaluation (Evaluasi berbasis tujuan). Evaluasi Berbasis Tujuan dikembangkan oleh Ralph W. Tyler. Tyler mendefinisikan evaluasi sebagai “... the process of determining to what extent the educational objectives are actually being realized" (Brinkerhoff et. al, 1983). Evalausi merupakan proses menentukan sampai seberapa tinggi tujuan pendidikan sesungguhnya dapat dicapai.

Tyler menyebutkan bahwa penilaian pendidikan sebagai sebuah proses untuk menentukan sejauh mana tujuan-tujuan pendidikan dari program sekolah atau kurikulum tercapai. Evaluasi berorientasi program dari Tyler ini didesain untuk menggambarkan sejauh mana tujuan program telah dicapai. Tyler menggunakan kesenjangan antara apa yang diharapkan dan apa yang berhasil diamati untuk memberikan masukan terhadap kekurangan dari suatu program. Pendekatan ini memfokuskan pada tujuan spesifik dari program dan sejauh mana prorgam ini telah berhasil mencapai tujuan tersebut.

Jenis evaluasi berbasis tujuan dirancang dan dilaksanakan dengan langkahlangkah sebagai berikut:

1. Mengindetifikasi tujuan. Mengidentifikasi dan mendefinisikan tujuan atau intervensi, layanan dari program yang tercantum dalam rencana program. Objektif program kemudian dirumuskan dalan indikator-indikator kuantitas dan kualitas yang dapat diukur.

2. Merumuskan tujuan menjadi indikator-indikator. Evaluator merumuskan tujuan program menjadi indikator-indikator kuantitatif dan kualitatif yang dapat diukur.

3. Mengembangkan metode dan instrumen untuk menjaring data. Evaluator menentukan apakah akan menggunakan metode kualitatif atau kuantitatif atau campuran. Mengembangkan instrumen untuk menjaring data.

4. Memastikan progam telah berakhir dalam mencapai tujuan. Layanan, intervensi darai program telah dilaksanakan dan ada indikator mencapai pencapaian tujuan, pengaruh atau perubahan yang diharapkan.

5. Menjaring dan menganalisis data/informasi pencapaian program, atau pengaruh intervensi atau perubahan yang diharapkan dari pelaksanaan 
program dan membandingkan dengan objektif yang direncanakan dalam rencana program untuk menentukan apakah terjadi ketimpangan.

6. Mengambil keputusan mengenai program.

Keputusan dapat berupa; a) jika program dapat mencapai tujuannya sepenuhnya, program dilanjutkan atau dilaksanakan di daerah lain, b) Jika program berhasil dan masyarakat sudah tidak memerlukan lagi maka program dihentikan, c) Jika program gagal, tetapi masih diperlukan oleh sebagian besar masyarakat, maka program dianalisis penyebab kegagalan dan kemudian dikembangkan dan dimodifikasi. (Wirawan, 2011)

\section{METODE}

Metode penelitian ini menggunakan metode evaluasi program goal-based evaluation yang diterapkan pada program GLS. Subjek evaluasi program GLS adalah masyarakat sekolah tingkat SD, SMP, dan SMA sederajat se-Indonesia yang mencakup kepala sekolah, guru, karyawan, dan siswa. Waktu penelitian dilakukan pada bulan Maret sampai Mei 2018.

Langkah-langkah evaluasi yang dilakukan disesuaikan dengan langkahlangkah sebagai berikut:

1. Mengindetifikasi tujuan dilakukan dengan melakukan studi pustaka terkait tujuan nasional GLS.

Adapun tujuan umum GLS adalah Menumbuhkembangkan budi pekerti peserta didik melalui pembudayaan ekosistem literasi sekolah yang diwujudkan dalam Gerakan Literasi Sekolah agar mereka menjadi pembelajar sepanjang hayat.

Tujuan khusus GLS adalah sebagai berikut:

a. Menumbuhkembangkan budaya literasi membaca dan menulis siswa di sekolah

b. Meningkatkan kapasitas warga dan lingkungan sekolah agar literat

c. Menjadikan sekolah sebagai taman belajar yang menyenangkan dan ramah anak agar warga sekolah mampu mengelola pengetahuan

d. Menjaga keberlanjutan pembelajaran dengan menghadirkan beragam buku bacaan dan mewadahi berbagai strategi membaca 
2. Tujuan yang diperoleh dari tahap identifikasi dijabarkan menjadi indikatorindikator.

Tujuan utama evaluasi ini adalah untuk mengetahui keterlaksanaan program GLS di sekolah dan digunakan sebagai bahan evaluasi program secara menyeluruh dan digunakan sebagai bahan perbaikan kegiatan program GLS ke depan.

Indikator-indikator jabaran tujuannya adalah:

a. Pengetahuan dasar terkait definisi GLS, keberadaan apakah program tersebut ada di sekolah responden, dan urgensi GLS.

b. Implementasi terkait alokasi waktu yang disediakan sekolah, bahan bacaan, antusias, dan kondisi lingkungan.

c. Kebutuhan dan saran terkait masukan program GLS kedepan.

3. Membuat instrumen. Instrumen pengambilan data yang digunakan adalah angket.

Tabel 1. Angket Gerakan Literasi Sekolah (GLS)

\begin{tabular}{|c|c|}
\hline BAGIAN & PERTANYAAN \\
\hline Bagian 1 & $\begin{array}{l}\text { IDENTITAS } \\
\text { 1. Saya mengisi sebagai? } \\
\text { a. Kepala sekolah } \\
\text { b. Guru } \\
\text { c. Karyawan } \\
\text { d. siswa } \\
\text { 2. Identitas } \\
\text { a. Nama } \\
\text { b. Sekolah } \\
\text { c. Alamat sekolah } \\
\text { d. Jenis kelamin } \\
\text { e. No. HP }\end{array}$ \\
\hline Bagian 2 & $\begin{array}{l}\text { PENGETAHUAN DASAR } \\
\text { 1. Apakah anda mengetahui gerakan literasi sekolah } \\
\text { (GLS)? } \\
\text { a. Ya } \\
\text { b. Tidak } \\
\text { 2. Apakah di sekolah anda terdapat kegiatan yang } \\
\text { membiasakan masyarakatnya membaca? } \\
\text { a. Ya } \\
\text { b. tidak } \\
\text { 3. Menurut pendapat anda, perlukah membiasakan } \\
\text { membaca di lingkungan sekolah? } \\
\text { a. Ya } \\
\text { b. Tidak }\end{array}$ \\
\hline Bagian 3 & $\begin{array}{l}\text { IMPLEMENTASI } \\
\text { 1. Berapa menit alokasi waktu yang digunakan pada } \\
\text { kegiatan membaca? } \\
\text { a. Kurang dari } 10 \text { menit }\end{array}$ \\
\hline
\end{tabular}




\begin{tabular}{|c|c|}
\hline & $\begin{array}{l}\text { b. } 10 \text { sampai } 20 \text { menit } \\
\text { c. } 20 \text { sampai } 30 \text { menit } \\
\text { d. Lebih dari } 30 \text { menit } \\
\text { 2. Bahan bacaan yang sering kalian baca saat gerakan } \\
\text { berlangsung adalah? } \\
\text { a. Novel } \\
\text { b. Majalah } \\
\text { c. Koran } \\
\text { d. Buku Pengetahuan Umum Selain Pelajaran } \\
\text { e. Buku Keagamaan } \\
\text { f. lain-lain } \\
\text { 3. Saat kegiatan berlangsung, berapa banyak perkiraan } \\
\text { jumlah halaman buku yang mampu kalian baca? } \\
\text { a. Kurang dari } 3 \\
\text { b. } 3 \text { sampai } 5 \text { halaman } \\
\text { c. Lebih dari } 5 \text { halaman } \\
\text { Apakah saya membaca saat kegiatan berlangsung? } \\
\text { a. Ya } \\
\text { b. Tidak } \\
\text { Apakah kondisi sekolah kondusif "tidak bising" saat } \\
\text { kegiatan berlangsung? } \\
\text { a. Ya } \\
\text { b. Tidak } \\
\text { Saya akan menegur jika ada ada teman, guru, } \\
\text { karyawan, ataupun kepala sekolah yang tidak } \\
\text { membaca pada saat kegiatan literasi? } \\
\text { a. Ya } \\
\text { b. Tidak } \\
\text { 9. Kenurut anda, setujukah kalian jika kegiatan } \\
\text { membaca dilakukan menggunakan media HP atau } \\
\text { laptop atau elektronik? } \\
\text { a. Ya } \\
\text { b. Tidak } \\
\text { 6emukaan pendapatmu? }\end{array}$ \\
\hline Bagian 4 & $\begin{array}{l}\text { KEBUTUHAN DAN SARAN } \\
\text { 1. Perlukah kegiatan ini dilanjutkan di sekolah anda? } \\
\text { a. Ya } \\
\text { b. Tidak } \\
\text { 2. Tuliskan saran terhadap kegiatan literasi yang } \\
\text { diterapkan di sekolahmu untuk bahan perbaikan ke } \\
\text { depan! }\end{array}$ \\
\hline
\end{tabular}

4. Mengambil data. Proses pengambilan data dilakukan dengan menggunakan google form, dan menyebarkannya melalui media sosial untuk memperoleh responden sebanyak-banyaknya. Batas minimum responden yang ditetapkan adalah minimal 50 siswa dengan minimal 10 sekolah yang tersebar di Indonesia.

5. Menganalisis data. Tahapan ini dilakukan olah data sederhana dengan pendekatan analisis data deskriptif kuantitatif. 
6. Mengambil keputusan mengenai program. Pengambilan keputusan dilakukan setelah diperoleh kesimpulan dari analisa data angket atau kuisioner. Keputusan yang diambil dicocokkan dengan tujuan dari GLS dan penentuan terkait saran untuk kelanjutan program ataupun pemberhentian program.

Teknik pengumpulan data yang digunakan pada evaluasi ini adalah dengan menggunakan angket dengan bantuan google form. Analisa data dilakukan dengan pendekatan deskriptif kuantitatif dengan statistik sederhana dan penyajian data seperti diagram batang.

\section{HASIL DAN PEMBAHASAN}

\section{Ringkasan Tanggapan Responden}

Dari 76 responden yang mengisi form, diperoleh nilai prosentase responden sebagai berikut!

Saya mengisi sebagai?

76 tanggapan

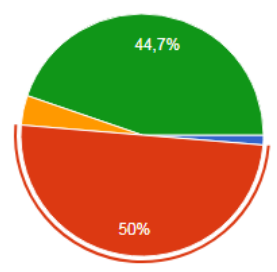

Kepala sekol

- Karu

Karyawa

Gambar 8. Diagram lingkaran responden

Tabel 2. Hasil Pengisian Berdasarkan Responden

\begin{tabular}{|c|c|c|c|c|}
\hline Responden & $\begin{array}{c}\text { Kepala } \\
\text { sekolah }\end{array}$ & Guru & Karyawan & Siswa \\
\hline $\begin{array}{c}\text { Jumlah } \\
\begin{array}{c}\text { Prosentase } \\
\text { (\%) }\end{array}\end{array}$ & 1 & 38 & 3 & 34 \\
\hline
\end{tabular}

Responden paling banyak berasal dari kalangan guru, hal ini dikarenakan informasi pengisian angket ini disebarkan lewat jejaring sosial yang berisi grup guru. Responden berasal dari 39 Sekolah yang tersebar di Indonesia, dengan sebaran berikut:

Tabel 3. Sebaran tingkatan sekolah responden

\begin{tabular}{|c|c|c|c|}
\hline Tingkatan & SD/sederajat & SMP/sederajat & SMA/sederajat \\
\hline Jumlah & 7 & 6 & 26 \\
\hline
\end{tabular}


Widayoko, A., H, S., \& Muhardjito, M. (2018). ANALISIS PROGRAM IMPLEMENTASI GERAKAN LITERASI SEKOLAH (GLS) DENGAN PENDEKATAN GOAL-BASED EVALUATION. Jurnal Tatsqif, 16(1), 78-92. Retrieved from http://journal.uinmataram.ac.id/index.php/tatsqif/article/view/134

Sebaran jenis kelamin responden laki-laki 36 dan perempuan 40, sebagai berikut:

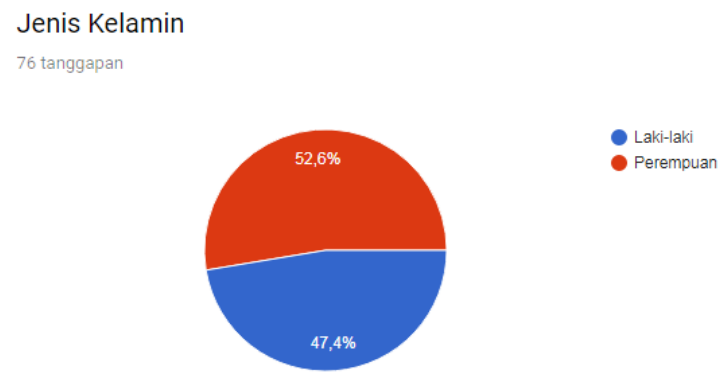

Gambar 9. Sebaran jenis kelamin

\section{Hasil Pengetahuan Dasar GLS}

Apakah anda mengetahui gerakan literasi sekolah (GLS)? 76 tanggapan

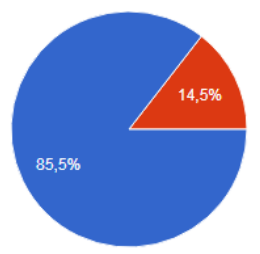

Gambar 10. Diagram lingkaran Pengetahuan tentang GLS

Berdasarkan gambar 10, terkait pengetahuan dasar GLS, sebagian besar responden mengetahui GLS. Prossentase responden yang mengetahui GLS sebesar $85.5 \%$ dan sisanya $14.5 \%$ tidak mengetahui gerakan literasi sekolah atau GLS.
Apakah di sekolah anda terdapat kegiatan yang membiasakan masyarakatnya membaca?

76 tanggapan

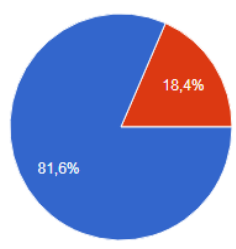

Ya

Gambar 11. Diagram lingkaran terlaksana kegiatan GLS

Pada gambar 11, 81.6\% responden menyatakan terdapat aktivitas membiasakan membaca di lingkungan sekolahnya. Prosentase ini lebih kecil dari prosentase pengetahuan dasar GLS yaitu 85.5\%, hal ini mengindikasikan bahwa ada responden yang mengetahui GLS namun di sekolahnya tidak dilaksanakan kegiatan membaca yang merupakan implementasi dari GLS. 
Widayoko, A., H, S., \& Muhardjito, M. (2018). ANALISIS PROGRAM IMPLEMENTASI GERAKAN LITERASI SEKOLAH (GLS) DENGAN PENDEKATAN GOAL-BASED EVALUATION. Jurnal Tatsqif, 16(1), 78-92. Retrieved from http://journal.uinmataram.ac.id/index.php/tatsqif/article/view/134

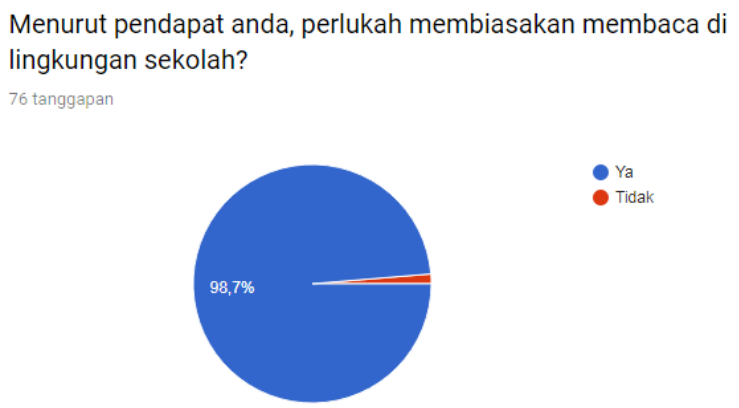

Gambar 12. Pendapat responden tentang membiasakan membaca

Pada gambar 12, terlihat bahwa sebesar 98.7\% mengatakan perlu membiasakan membaca dilingkungan sekolah.

\section{Hasil Implementasi GLS}

Berapa menit alokasi waktu yang digunakan pada kegiatan membaca? 6 tanggapa
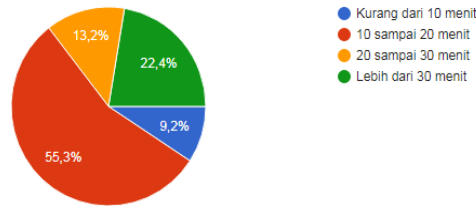

- Lebin dari 30 menit

Gambar 13. Alokasi waktu
Bahan bacaan yang sering kalian baca saat gerakan berlangsung adalah?
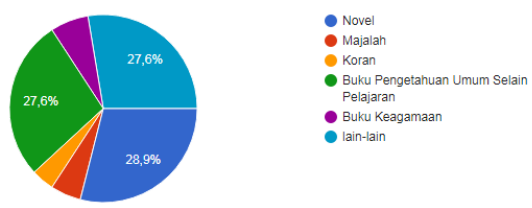

Gambar 14. Jenis bacaan

Berdasarkan gambar 13, diketahui Bahan bacaan novel masih menjadi bahwa alokasi waktu yang sekolah pilihan utama responden dalam mengisi alokasikan dalam kegiatan membaca ini kegiatan GLS yaiutu sebesar 28.9\%, adalah sekitar 10-20 menit dengan diikuti oleh pengetahua umum dan lainprosentase $56.3 \%$. Hal ini sesuai dengan lain.

arahan dari pemerintah pusat terkait alokasi membaca 25 menit sebelum pembelajaran. 
Saat kegiatan berlangsung, berapa banyak perkiraan jumlah halaman buku yang mampu kalian baca?
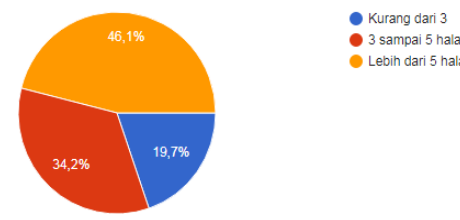
Lebih dari 5 halaman

Gambar 15. Perkiraan jumlah halaman

Dari gambar 15, diketahui bahwa dalam alokasi waktu antara 10-20menit, responden rata-rata membaca 3 sampai 5 halaman. Jika dibuat rata-rata, untuk 15 menit alokasi dan responden membaca maksimal 5 halaman, hal ini berarti bahwa dalam 1 halaman responden membutuhkan waktu 3 menit. Alokasi waktu 3 menit setiap halaman masih menunjukkan bahwa pembiasaan membaca perlu ditingkatkan lagi. Ini merupakan suatu temuan untuk penelitian lebih lanjut.

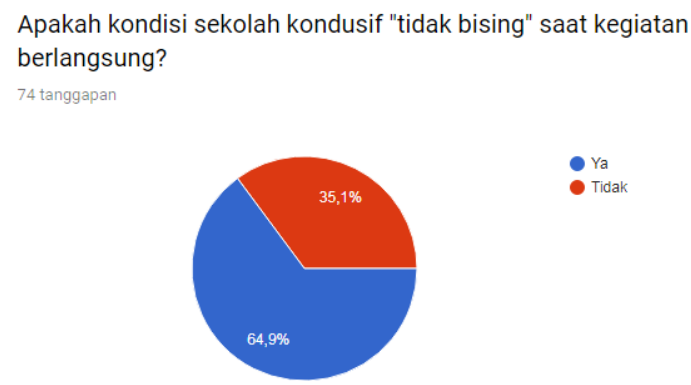

Gambar 17. Kondisi sekolah

Berdasarkan gambar 17, kondisi sekolah dalam melaksanakan kegiatan GLS 64.9\% mengatakan kondusif untuk memaksimalkan penyelenggaraan GLS.
Apakah saya membaca saat kegiatan berlangsung? 74 tanggapan

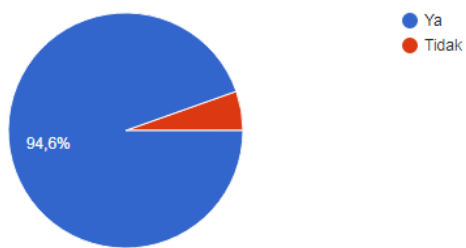

Gambar 16. Kesungguhan diri dalam menerapkan GLS

Dari gambar 16, siswa secara umum membaca dalam pembiasaan membaca 15 menit di sekolah sebelum pembelajaran. ini juga merupakan suatu temuan baru untuk penelitian lebih lanjut terkait kesungguhan responden dalam membaca.

Saya akan menegur jika ada ada teman, guru, karyawan, ataupun kepala sekolah yang tidak membaca pada saat kegiatan literasi? 75 tanggapan

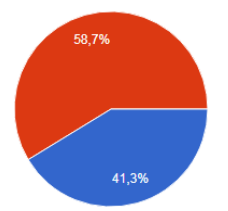

- Yidak

Gambar 18. Respeksibeliti responden terhadap pelaksanaan GLS

Berdasarkan gambar 18, tingkat respeksibilitas responden dalam implementasi belum tergolong tinggi. Tujuan dari pertanyaan ini adalah untuk mengetahui kepedulian responden 
terhadap pelaksanaan program GLS. Hasil ini mengindikasikan bahwa kepedulian terhadap pelaksanaan GLS belum tergolong tinggi.

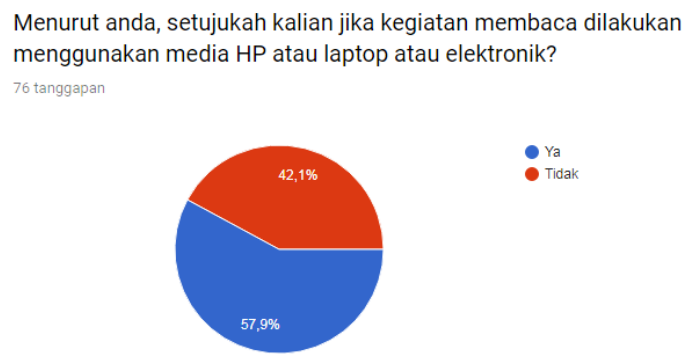

Gambar 19. Urgensi media membaca

Dari gambar 19, 57.9\% responden tidak setuju dengan media elektronik sebagai media membaca saat kegiatan GLS berlangsung. Berbagai alasan dikemukakan responden yang tidak setuju terkait penggunaan media elektronik. Beberapa alasan diantaranya, dengan membaca melalui media elektronik tidak membuat siswa fokus dalam membaca, menyalah-gunakan dengan kesempatan membuka media sosial, dan respon paling banyak adalah banyaknya berita hoax yang tidak bisa disaring oleh siswa.

\section{Hasil Kebutuhan dan Saran GLS}

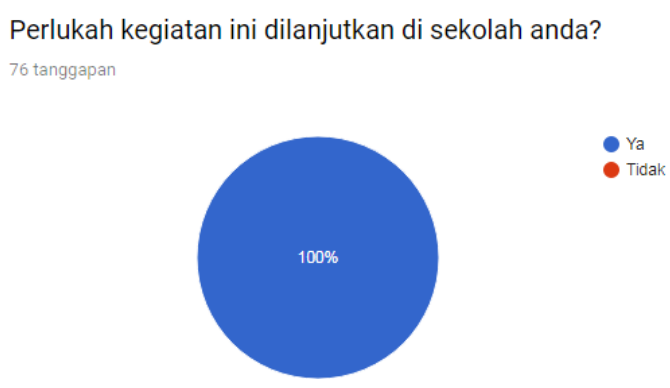

Gambar 20. Urgensi kegiatan

Gambar 20, menjelaskan bahwa urgensi kegiatan GLS sangat penting dilanjutkan. Semua responden sepakat untuk tetap melanjutkan kegiatan GLS.

Berdasarkan hasil analisis data yang dilakukan di atas. Dapat disimpulkan bahwa kegiatan GLS sudah sesuai dengan tujuan GLS nasional. Tujuan pertama yaitu 
Widayoko, A., H, S., \& Muhardjito, M. (2018). ANALISIS PROGRAM IMPLEMENTASI GERAKAN LITERASI SEKOLAH (GLS) DENGAN PENDEKATAN GOAL-BASED EVALUATION. Jurnal Tatsqif, 16(1), 78-92. Retrieved from http://journal.uinmataram.ac.id/index.php/tatsqif/article/view/134

menumbuhkembangkan budaya literasi membaca dan menulis siswa di sekolah, hal ini sudah terkasana dengan baik. Terlihat besar prosentase sekolah responden 85.5\% mengetahui GLS dan 81.6\% sekolah responden memiliki kegiatan membaca 15 menit sebelum pelajaran. Tujuan kedua yaitu meningkatkan kapasitas warga dan lingkungan sekolah agar literat. Hal ini juga sudah terlaksanakan sesuai tujuan, terlihat dari beragamnya responden yang terdiri dari kepala sekolah, guru, karyawan, dan siswa. Tujuan ketiga terkait dengan menjadikan sekolah sebagai taman belajar yang menyenangkan dan ramah anak agar warga sekolah mampu mengelola pengetahuan juga sudah terlaksana. Sebesar $64.9 \%$ responden mengatakan bahwa lingkungan sekolah sebagai temapt penyelenggaraan GLS sangat kondusif, hal ini juga mengindikasikan bahwa lingkunagn sekolah merupakan tempat belajar yang menyenangkan. Tujuan keempat yaitu menjaga keberlanjutan pembelajaran dengan menghadirkan beragam buku bacaan dan mewadahi berbagai strategi membaca. Hal ini tergambar pada hasil pertanyaan terkait keberlanjutan dan saran. $100 \%$ responden mengatakan bahwa program ini sangat baik, maka perlu dilanjutkan. Beberapa saran menyebutkan bahwa, pemerintah perlu menganggarkan untuk pembelian buku bacaan untuk menunjang GLS. Hal ini dikarenakan, banyak buku-buku di sekolah sudah tidak layak dan lama, sehingga diperlukan buku-buku baru untuk meningkatkan minat baca responden. Maka, secara keseluruhan gerakan GLS di sekolah responden sudah berjalan sesuai dengan tujuan GLS secara Nasional.

\section{KESIMPULAN}

Berdasarkan uraian, keterlaksanaan program GLS di sekolah sudah berjalan dengan baik, namun perlu beberapa perbaikan pada saat penerapannya. Perbaikan yang disarankan oleh responden kepada stakeholder diantaranya adalah pendisiplinan pelaksanaan, alokasi waktu ditambah, perlunya penambahan bukubuku koleksi terbaru untuk menunjang program GLS. Secara keseluruhan program sudah berjalan di berbagai sekolah, sehingga program ini perlu dilanjutkan untuk mencapai tujuan-tujuan GLS nasional.

Pendekatan evaluasi goal-based oriented bisa dilakukan untuk melakukan evaluasi program GLS yang disesuaikan dengan tujuan GLS nasional yang hendak di capai. Saran yang perlu peneliti sampaikan untuk peneliti selanjutnya adalah 
Widayoko, A., H, S., \& Muhardjito, M. (2018). ANALISIS PROGRAM IMPLEMENTASI GERAKAN LITERASI SEKOLAH (GLS) DENGAN PENDEKATAN GOAL-BASED EVALUATION. Jurnal Tatsqif, 16(1), 78-92. Retrieved from http://journal.uinmataram.ac.id/index.php/tatsqif/article/view/134

perlunya penelitian terkait implementasi GLS pada suatu sekolah dengan menggunakan evaluasi program lainnya.

\section{DAFTAR PUSTAKA}

Brinkerhoff, R.O., et.al, (1983). Program evaluation: A practitioner"s guide for trainers and educators. Western Michigan: Kluwer-Nijhoff.

Darodjat \& Wahyudhiana. (2015). Model Evaluasi Program Pendidikan. ISLAMADINA, XIV (1). 1-28.

Dirjendikdasmen. (2016). Desain Induk Gerakan Literasi Sekolah. Kemendikbud

Dirjendikdasmen. (2015). Buku Saku Gerakan Literasi Sekolah. Kemendikbud

Faizah, et. al. (2016). Panduan Gerakan Literasi di Sekolah Dasar. Jakarta: Dirjen Dikmen Kementrian Pendidikan.

OECD. (2017). PISA 2015 Assessment and Analitical Framework Science, Reading, Mathematic, Financial Literacy and Collaborative Problem Solving (Revised E). Paris : OECD Publishing.

Simpul. (2017). Nawacita (Sembilan Program Perubahan Untuk Indonesia). Bappenas: Simpul Perencana Vol. 29.

Wirawan. (2011). Evaluasi Teori Model Standar Aplikasi dan Profesi, Contoh Aplikasi Evaluasi Program: Pengembangan Sumber Daya Manusia, Program Nasional Pemberdayaan Masyarakat (PNPM) Mandiri Pedesaan, Kurikulum, Perpustakaan, dan Buku Tes. Jakarta: Raja Grafindo Persada. 